\title{
A HYDROGEN PEROXIDE CELL
}

BY H. T. BARNES AND G. W. SHEARER

The behaviour of aluminum and magnesium electrodes in water containing dissolved air, oxygen or hydrogen peroxide was first studied by one of the authors in conjunction with H. M. Tory ${ }^{1}$ and G. H. Cole. ${ }^{2}$ It was shown that an abnormally high electromotive force was developed between these two metals, which was connected with the presence of free oxygen in the water. Without oxygen only a small electromotive force existed, but the dissolving of so small an amount of that gas as could be obtained by bubbling air through the initially depleted water caused the voltage to rise from 0.02 to about one volt. The effect was traced to the aluminum electrode alone by measuring the electromotive force between two electrodes of the same metal in a cell divided into two compartments, one containing water free from air, and the other containing air-charged water. In every case the metal in the dissolved oxygen was the cathode. A number of metals was studied in this way, and a large or small effect observed. Aluminum, however, was conspicuous by the magnitude of the effect, and an electromotive force of nearly a volt could be maintained between two electrodes of aluminum, due merely to the action of the dissolved air.

Fig. I shows the two types of cells used to study this effect. In $A$ the vessel was a long glass tube with inlet holes at top and bottom, and an outlet hole in the middle. Airfree water from a flask of boiling water was let in at the top at any desired temperature, and air-charged water was let in at the bottom. Both streams flowed out the central orifice, where a line of separation was sharply maintained. The tube could also be completely flushed out, either with air-free or air-charged water. The electrodes passed through corks at

${ }^{1}$ Trans. Am. Electrochem. Soc, 3, 95 (rgo3).

2 Ibid., 12, 54 (1907). 
the top and bottom, and the difference of potential was measured on an electrometer. In the type B, two compartments were provided with inclined side tubes into which various electrodes could be thrust. Air-free or air-charged
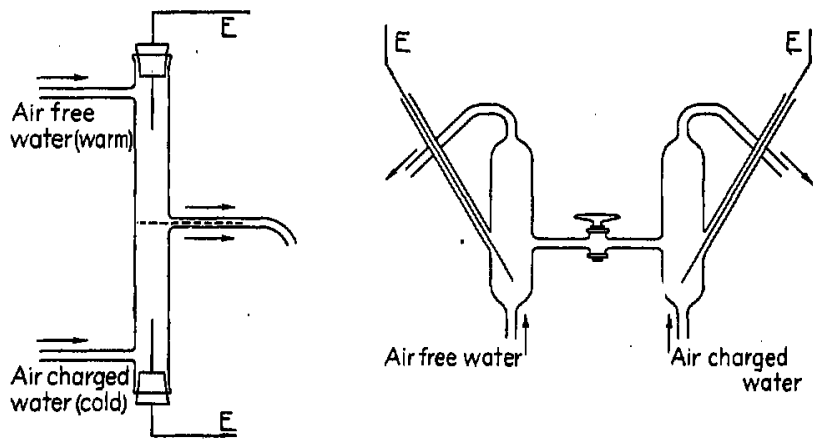

Fig. I.

water was run continuously through the compartmenis. The latter form was found more convenient when working with water at the same temperature in both sides.

It was found that the effect produced on different metals was additive, so that selecting a metal like magnesium high up in the electro-positive series which showed practically no difference in air-free or air-charged water, it was possible to get the effect of oxygen on any metal by measuring it against this metal in a single cell. Thus we selected the combination of magnesium with aluminum to further study the electromotive force produced in different electrolytes. As a cell it was found that the best results were obtained with a combination of

$$
\mathrm{Mg}-\mathrm{Al}_{2}\left(\mathrm{SO}_{4}\right)_{3}-\mathrm{Al}
$$

and that a considerable current could be obtained from the cell. With the addition of hydrogen peroxide, the electromotive force was further augmented to I.7 and even to 2.I volts.

A peculiar feature of this cell was a rise of electromotive force and current on closed circuit for a considerable time, and after passing through a maximum value, a gradual fall 
in value, but adding fresh hydrogen peroxide always sent the electromotive force and current up again to the maximum values. It was evident from early experiments ${ }^{1}$ that, on account of the direction of the current in the cell, the gradual rise was associated with the removal of the high resistance surface film from the aluminum, thereby exposing a clean surface of the metal, and that the fall was associated with a depletion of the $\mathrm{H}_{2} \mathrm{O}_{2}$, or oxygen ions, around the aluminum surface. Shaking the cell always sent the electromotive force up a little, but not so much as adding $\mathrm{H}_{2} \mathrm{O}_{2}$.

It is well known that aluminum as cathode allows current to pass freely, but as anode shows an abnormally high resistance. This has been fairly conclusively shown to be due to the formation of a thin film of hydroxide on the aluminum surface in the latter case, and its removal in the former.

Our cell behaved to outside currents just as we would expect if this were true. A current from a powerful storage battery sent for a short time through the cell, so as to make the aluminum the cathode, left the electromotive force of the cell at its high maximum value, while when passed in the other direction so as to form the anode film on the aluminum, left the electromotive force at its low initial value.

The question of the gradual rise of electromotive force and current in the cell was, therefore, not difficult to explain, but the abnormally high electromotive force produced between the two metals otherwise close together in the electrochemical series was not so easy to explain until Professor Bancroft suggested to one of the authors, that possibly the aluminum in the presence of dissolved oxygen generated $\mathrm{H}_{2} \mathrm{O}_{2}$, and thereby formed a cell with $\mathrm{H}_{2} \mathrm{O}_{2}$ as electrode. The reaction, he suggested, might take place as follows:

$$
2 \mathrm{Al}+6 \mathrm{H}_{2} \mathrm{O}+6 \mathrm{O} .=\mathrm{Al}_{2}(\mathrm{OH})_{6}+{ }_{3} \mathrm{H}_{2} \mathrm{O}_{2} \text {. }
$$

In this case, as soon as an aluminum plate was placed in water containing dissolved oxygen, the surface was oxidized and $\mathrm{H}_{2} \mathrm{O}_{2}$ generated. In order to test this point we placed

${ }^{1}$ Loc, cit., page 58 . 
some pure aluminum sheet in ordinary pure distilled water open to the air and thoroughly charged and after standing a few hours we applied the well-known KI and starch test for the peroxide with marked success. There was a comparatively strong reaction for hydrogen peroxide, while some of the same sample of water not in contact with aluminum showed absolutely no trace.

Having obtained evidence of the production of the peroxide, we found that the yield could be increased by using a considerable quantity of aluminum foil in small pieces and leaving it for two or three days in water through which air was bubbled. Mechanical agitation also helped the production. We obtained the greatest yield when we cooled the water by immersing the flask in cracked ice and at the same time sent a current through the water, making the mass of aluminum foil the anode and having a small aluminum wire as cathode. In this way we obtained a starch reaction of about the same apparent strength as a solution of the ordinary 3 percent hydrogen peroxide made up to a dilution of $\mathrm{I}$ or 2 drops in a liter of water. If a current was sent through the water so as to make the aluminum the cathode, no reaction for the peroxide could be obtained. In this case an anode of platinum was used.

The dependence of the hydrogen peroxide upon the presence of dissolved oxygen was shown very completely by the following test: A quantity of pure aluminum foil was boiled in distilled water. The heat was then removed and the flask tightly corked and allowed to cool for several hours. On opening the flask the water was quickly poured off from the foil and tested for peroxide without success. The same foil, however, when placed in water containing air developed $\mathrm{H}_{2} \mathrm{O}_{2}$ at once.

\section{Tests on the Peroxide Cell with Aluminum and Magnesium Electrodes}

The fact that aluminum metal develops hydrogen peroxide in contact with water, and free oxygen is sufficient to 
explain the abnormally high electromotive force that exists between aluminum and magnesium as well as other combinations. In the cell containing these electrodes as studied by one of us with $\mathrm{Mr}$. Cole, the addition of $\mathrm{H}_{2} \mathrm{O}_{2}$ serves merely to increase the concentration of the peroxide around the aluminum and thus to increase the effect. When the cell supplies current, the cathodic action of the aluminum is to remove the surface film and to decompose the peroxide. The first action is accompanied by an increase in electromotive force and current, and the depletion of peroxide is the cause of the slow falling off in electromotive force and current after the maximum value has been reached. The energy of the cell is at the expense of the magnesium which is changed to the hydroxide. We have represented in the following curves some of the tests on the cell, with and without hydrogen peroxide, and the effect of temperature.

Fig. 2 represents the rate of rise of current and voltage in a cell to whichino $\mathrm{H}_{2} \mathrm{O}_{2}$ has been added. The first portion of the scale is in hours up to 2 from which point on the time is

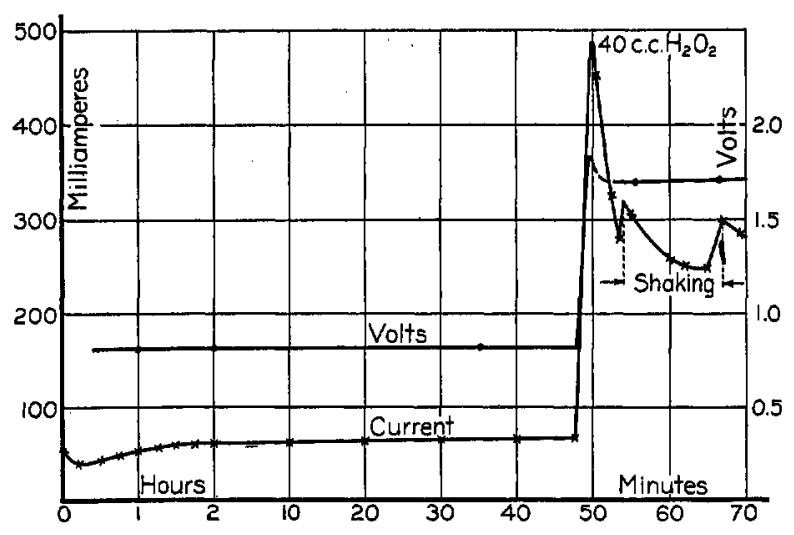

Fig. 2

expressed in minutes. The addition of $40 \mathrm{cc}$ of the ordinary 3 percent $\mathrm{H}_{2} \mathrm{O}_{2}$ is shown by the sudden rapid rise both in current and in electromotive force. A very rapid fall is 
shown to take place, after which a more gradual drop follows. The effect of shaking the cell is shown at two points. The voltmeter readings were not taken often enough for a complete curve. In the previous paper with Mr. Cole complete voltage and current curves are given for a special form of this cell.

Fig. 3 shows the effect of temperature on the voltage and current from the cell with no $\mathrm{H}_{2} \mathrm{O}_{2}$ added. At the point marked "heat removed," the cell was at the boiling-point

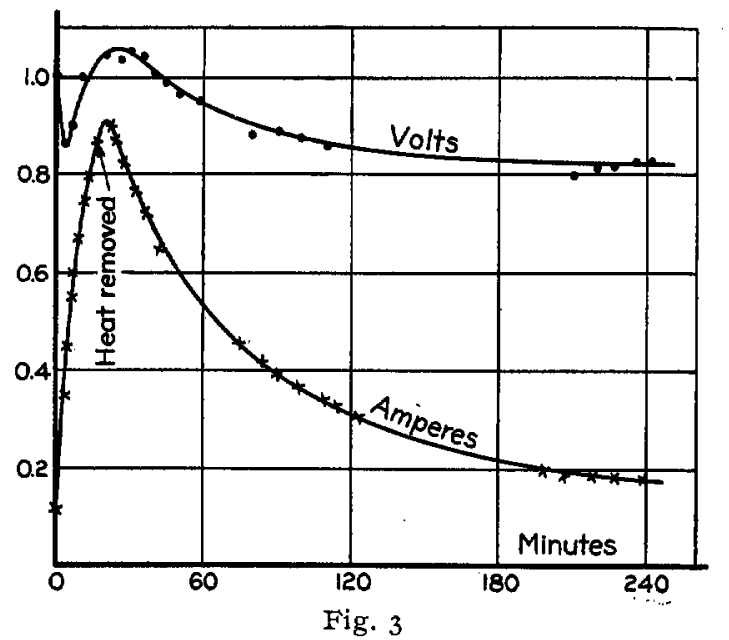

and then allowed to cool. The current increased very rapidly with temperature from 0.14 ampere to nearly an ampere. At the boiling-point the effervescence became quite violent.

Fig. 4 shows a similar set of readings, but in addition 20 cc of the 3 percent $\mathrm{H}_{2} \mathrm{O}_{2}$ was added when the cell was at the boiling-point. A sudden rise both in voltage and in current is then followed by as sudden a drop to normal conditions, probably owing to the rapid decomposition of the $\mathrm{H}_{2} \mathrm{O}_{2}$.

Fig. 5 shows the electromotive force and current curves on a temperature base with no $\mathrm{H}_{2} \mathrm{O}_{2}$ added. 


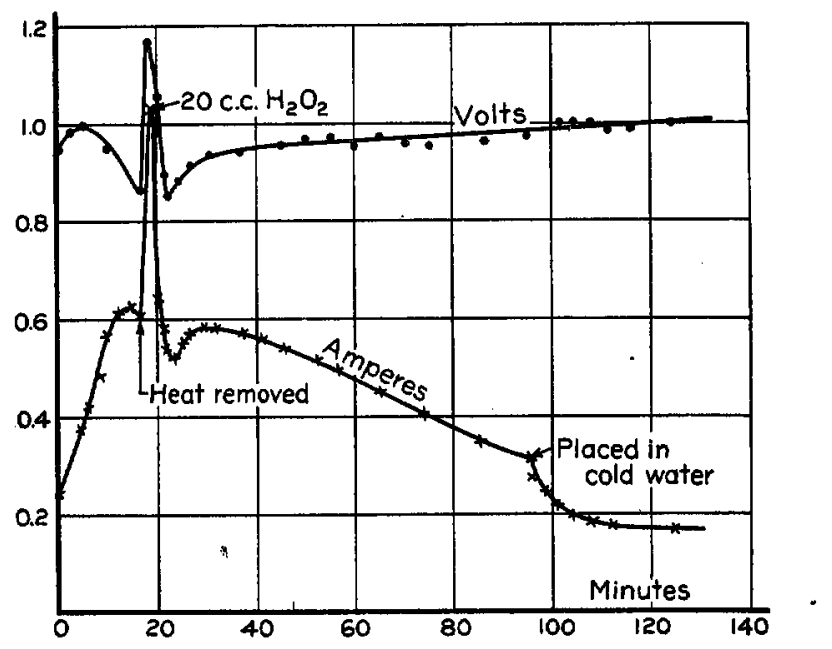

Fig. 4

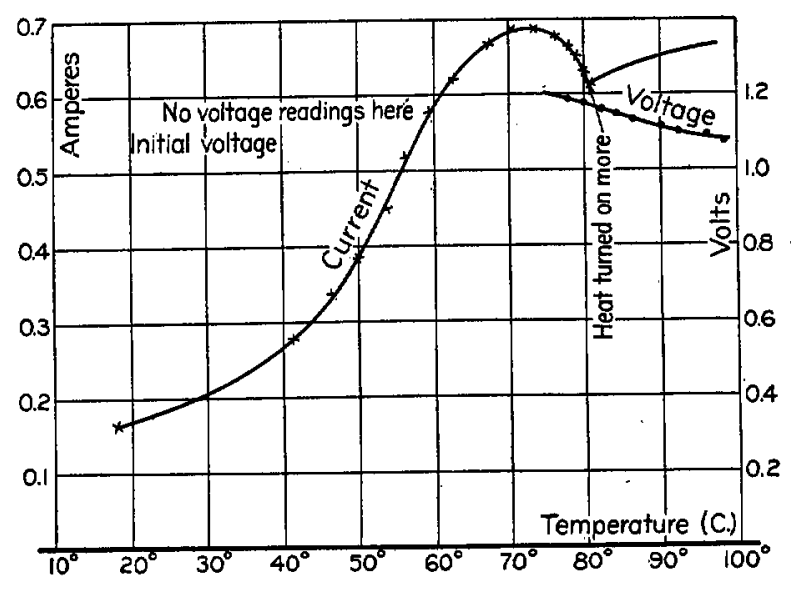

Fig. 5

\section{Conclusion}

We have concluded from this and previous studies of aluminum electrodes that a surface film is formed over all surfaces of this metal exposed to air or water and that the reaction in the case of water develops hydrogen peroxide. 
The presence of the peroxide thus formed explains the peculiar behaviour of the aluminum and magnesium cell. The reaction between aluminum and water is such as to suggest a composition for the surface film of $\mathrm{Al}_{2}(\mathrm{OH})_{8}$.

Although it has been stated that hydrogen peroxide is produced from several metals in contact with water, notably zinc and iron, we were unable to detect it in the case of zinc, treated in a similar way to our aluminum metal. If dissolved air produces a similar effect on other metals and thus gives rise to the potential effects which we observed on nearly all the metals examined, then it is likely to be too small in amount to be detected by the starch and iodine reaction.

McGill University, Dec. I6, 1907 . 